\title{
Brucelose canina: obtenção de antígenos e avaliação pela técnica de imunodifusão em gel de agarose
}

\author{
Canine Brucellosis: antigen obtention and evaluation by Agar Gel \\ Immunodiffusion
}

Teresinha Ferreira, ${ }^{*}$ Márcio José de Figueiredo, ${ }^{*}$ Mario Augusto Ronconi, ${ }^{*}$ Helenita Marques Torres, ${ }^{*}$ Maria Helena
Cosendey de Aquino, ${ }^{*}$ Marcos Jose Pereira Gomes, ${ }^{* \star}$ Marlom Vicente da Silva, ${ }^{* \star *}$ Luiz Antônio Trindade de Oliveira*

\begin{abstract}
Resumo
Cães com brucelose causada por Brucella canis apresentam poucos sinais importantes de doença sistêmica e nenhum deles específico para brucelose. Devido às limitações dos procedimentos bacteriológicos, casos suspeitos devem ser avaliados sorologicamente. $O$ objetivo deste estudo foi avaliar a utilização de antígenos externos e internos de Brucella canis e de Brucella ovis, pelo teste de imunodifusão em gel de agarose (IDGA). Antígenos externos e internos foram extraídos por solução salina tamponada e fosfatada (PBS) a quente a partir das cepas RM 6/66 de Brucella canis e REO 198 de Brucella ovis cultivadas em Ágar e Caldo Tripticase soja (Meio de Castañeda). Os antígenos externos foram obtidos após centrifugação e concentração do sobrenadante por ultrafiltração. Simultaneamente os sedimentos foram submetidos ao ultra-som e centrifugados sendo a porção sobrenadante considerado o extrato cru sonicado de $B$. canis e de $B$. ovis (antígeno interno). Soro hiperimune anti $B$. canis e anti $B$. ovis foram obtidos por inoculação intraperitoneal em coelhos ( $B$. canis e $B$. ovis), em cadela (B. canis) e em ovelha (B. ovis ) sendo utilizados como controles positivos na avaliação diagnóstica. Para referenciar os antígenos produzidos utilizou-se, ainda, soros de cães provenientes de um canil comercial localizado no Rio de Janeiro, RJ, suspeito de infecção brucélica pela ocorrência de abortos e natimortos. Houve resposta sorológica aos antígenos obtidos e a enfermidade foi confirmada por isolamento do agente etiológico, a partir de hemoculturas, em três animais do canil. Concluiuse que os antígenos externos apresentaram melhor resposta em animais experimentalmente inoculados e em naturalmente infectados, mas a confirmação deve ser feita com o antígeno sonicado.
\end{abstract}

Palavras-chave: diagnóstico, Brucella canis, Brucella ovis.

\begin{abstract}
Dogs with Brucellosis caused by Brucella canis have few proeminents signs of systemic illness and none of them may be specific for Brucellosis. Because of the limitation of bacteriologic procedures on suspected cases serologic tests are necessary. The objective of this study was to evaluate the utilization of external and internal antigen of Brucella canis and Brucella ovis by Agar Gel Immunodiffusion Test, contributing to the improvement of the canine Brucellosis diagnosis as well. External and internal antigen were extracted from cultures of $B$. canis (RM 6/66) and B. ovis (REO 198) on Soy Tripticase broth and agar (Castañeda) by hot phosphated buffered saline (PBS) extraction. The external antigens were obtained after centrifugation and concentration of the supernatant by ultrafiltration. Simultaneously, the pellets were sonicated and centrifuged and the supernatant portion was designated as crude sonicated antigen extract for both $B$. canis and $B$. ovis (internal antigens). Hiperimune sera for $B$. canis and $B$. ovis were obtained by intraperitoneal inoculation of bitch ( $B$. canis) and ewe ( $B$. ovis) and served as positive controls for diagnosis judgements. Additional sera from dogs of a kennel from Rio de Janeiro city, presenting Brucellosis symptoms, as abortion and stillbirth were investigated. Brucellosis was diagnosed by immunodiffusion seroconvertion and isolation of $B$. canis on blood cultures of three dogs as well. The external antigen yielded accurate results by using sera from experimentally and naturally infected animals, however, the diagnosis has to be confirmed by sonicated antigen using.
\end{abstract}

Keywords: diagnosis, B. ovis, B. canis

\section{Introdução}

A brucelose é uma zoonose cosmopolita causada por bactérias do gênero Brucella. Atualmente existem sete espécies reconhecidas, dentro do gênero, baseadas em suas carac- terísticas culturais, metabólicas, antigênicas e na especificidade do hospedeiro (Corbel, 1997). A espécie canina pode ser afetada pela maioria das espécies do gênero Brucella, mas a que demonstra real especificidade é a Brucella canis, que foi identificada por Carmichael (1966), a partir do

\footnotetext{
* Faculdade de Veterinária da Universidade Federal Fluminense - Rua Vital Brazil Filho, 64 - Sta. Rosa - Niterói, RJ. CEP 24230-340. natlua2004@yahoo.com.br

** Faculdade de Veterinária da Universidade Federal do Rio Grande do Sul, RS.

***Instituto de Medicina Veterinária Jorge Vaistman, Rio de Janeiro, RJ.
} 
abortamento de cadelas da raça Beagle, em canil nos Estados Unidos. Este pesquisador, inclusive, confirmou a sua patogenia para o homem e caracterizou definitivamente o cão como reservatório dessa bactéria (Germano et al., 1987). Embora o homem seja considerado resistente à Brucella canis, mais de 35 casos de infecção foram reportados e a maioria está relacionada com pessoas que manipulam o microrganismo em laboratórios ou através de cães infectados, geralmente, de sua propriedade (Johnson e Walker, 1992; Shapiro e Wong, 1999).

A infecção por Brucella canis é responsável por abortos epizoóticos em canis, principalmente os de criação comercial onde se instala, a seguir, de forma enzoótica, trazendo graves prejuízos econômicos. Os machos apresentam epididimite, dermatite escrotal, atrofia testicular, prostatite e, ocasionalmente, linfoadenopatia (Gomes et al., 1999).

Os produtos afetados pela enfermidade podem ser natimortos ou fracos, morrendo dentro de poucas horas ou poucos dias após o nascimento e os sobreviventes, aparentemente saudáveis, podem apresentar infartamento ganglionar (Currier et al., 1982). Entretanto, a maioria dos cães acometidos pela brucelose é assintomática, sendo o diagnóstico clínico da infecção bastante difícil. O único método realmente seguro para o diagnóstico da enfermidade é o isolamento do agente através do sangue, descargas vaginais, leite e sêmen de animais infectados, muito embora vários fatores inerentes às dificuldades técnicas de realização, bem como à evolução da própria enfermidade, afetem o sucesso desse procedimento. Embora a bacteremia seja prolongada, variando de dois até cinco anos ou mais, podem ocorrer períodos abacterêmicos e uma cultura de sangue negativa não pode ser usada como critério para a exclusão de brucelose canina. Considerando todos esses fatores, os testes sorológicos são os métodos mais comumente utilizados para avaliar o estado do cão antes do cruzamento ou quando se suspeita de brucelose canina (Lucero et al., 2002). Esses testes, entretanto, necessitam de criteriosa avaliação no que concerne à interpretação de seus resultados, uma vez, que dependendo do tipo de antígeno utilizado e da fase evolutiva da doença ou de infecções com bactérias diferentes de Brucella, pode-se observar resultados falso-positivos ou falso-negativos.

Os testes sorológicos mais empregados no diagnóstico laboratorial da Brucelose canina, causada pela $B$. canis, incluem o Teste de Soro Aglutinação em Tubos (SAT) e o Teste de Soro Aglutinação Rápida em Lâmina (SAR), com ou sem a adição de Mercapthoetanol (2-ME) e a Prova de Imunodifusão em Gel de Agarose (IDGA). Dois tipos de antígenos são utilizados para a prova de IDGA: um extraído do lipopolissacarídio (LPS) da parede celular de $B$. canis e outro que utiliza proteínas solúveis extraídas do citoplasma bacteriano (Mateo-deAntonio et al., 1994).

No Brasil, a técnica padrão para o diagnóstico sorológico da Brucelose canina é a IDGA utilizando um antígeno constituído de proteínas e lipopolissacarídios extraidos de $B$. ovis, amostra REO 198. Esse antígeno é fabricado pelo Instituto de Tecnologia do Paraná (TECPAR), distribuído pelo Ministério de Agricultura, Pecuária e Abastecimento (MAPA) e apresenta reação cruzada com a $B$. canis.

Em função disso, o objetivo do presente trabalho foi desenvolver e avaliar antigenos externos e internos (citoplasmáticos), extraídos, respectivamente, por salina tamponada e fosfatada (PBS) a quente e por ultra-som, a partir de amostras de $B$. ovis e $B$. canis, para serem utilizados nos testes de IDGA, com vistas a contribuir para o diagnóstico da brucelose canina.

\section{Material e métodos}

Esse experimento foi realizado no Laboratório da Disciplina de Doenças Infecciosas dos Animais Domésticos da Faculdade de Veterinária da Universidade Federal Fluminense-UFFRJ e no Instituto de Medicina Veterinária Jorge Vaistman-RJ.

Foram utilizadas as cepas liofilizadas de B. ovis REO 198 e de $B$. canis RM 6/66 oriundas do Instituto Panamericano de Protección de Alimentos y Zoonosis -INPPAZ - Argentina (antigo Centro de Controle de Zoonoses - CEPANZO).

As amostras bacterianas foram cultivadas em placas de Petri contendo Ágar Brucella (DIFCO) suplementado com $10 \%$ de soro normal de eqüino, sendo incubadas por três a cinco dias à temperatura de $35^{\circ} \mathrm{C}\left( \pm 2^{\circ} \mathrm{C}\right)$, em aerobiose. A pureza do cultivo foi avaliada pela morfologia das colônias após exame de esfregaços corados pelo método de Gram e com o auxílio das provas de hidrólise da uréia, produção de $\mathrm{H}_{2} \mathrm{~S}$, catalase e oxidase.

\section{Obtenção de antígenos externos}

A obtenção dos antígenos se fundamentou na técnica preconizada por Zoha e Carmichael (1982b) com algumas modificações. Cepas de $B$. ovis e de $B$. canis foram cultivadas em 10 garrafas de Roux com capacidade de $1 \mathrm{~L}$, contendo $100 \mathrm{~mL}$ de Ágar Brucella suplementado com $10 \%$ de soro normal de eqüino, sendo incubadas por três a cinco dias a $35^{\circ} \mathrm{C}\left( \pm 2^{\circ} \mathrm{C}\right)$ em aerobiose. Após crescimento, realizou-se uma lavagem da superfície do ágar com $20 \mathrm{~mL}$ de PBS, por garrafa, filtrando-se em seguida, em gaze dupla estéril. Estimou-se a concentração bacteriana, utilizando-se a técnica de centrifugação em microhematócrito, obtendo-se massa de $7 \%$ para $B$. ovis e $5 \%$ para $B$. canis. As suspensões foram, então, aquecidas a $65^{\circ} \mathrm{C}$, em banho-maria por duas horas, sob agitação e em seguida centrifugadas por $90 \mathrm{~min}$ a $15000 \times \mathrm{g}$ em centrífuga MR 22 i (JOUAN) a $4^{\circ} \mathrm{C}$ sendo os sedimentos reservados e os sobrenadantes, então, concentrados para $20 \mathrm{~mL}$, por ultrafiltração (Stirred Cell) em membrana YM 30.000 Da (AMICON). Os materiais assim concentrados foram designados antígenos externos de $B$. ovis (AEO) e de $B$. canis (AEC) extraídos por PBS a quente, liofilizados em frascos ampolas com rolha perfurável, em aparelho Modulyo (SAVANT) e corresponderam aos antígenos desenvolvidos por Zoha e Carmichael (1982b) sendo mantidos a $-20^{\circ} \mathrm{C}$ até o momento do uso.

\section{Obtenção de àntígenos com auxilio de ultra-som}

Os sedimentos obtidos na etapa anterior foram ressuspensos, respectivamente, em $60 \mathrm{~mL}$ de PBS e submetidos a banho de ultra-som durante $30 \mathrm{~min}$ em aparelho modelo $T_{7}$ (THORNTON ), potência $70-80 \mathrm{~Hz}$; sendo então centrifugados a $15000 \times \mathrm{g}$, durante $90 \mathrm{~min}$ em centrifuga a $4^{\circ} \mathrm{C}$ e os sobrenadantes concentrados para $14 \mathrm{~mL}$, por ultrafiltração em membrana YM 30000 Da (AMICON). Posteriormente foram liofilizados, sendo mantidos $\mathrm{a}-20^{\circ} \mathrm{C}$ até o momento do uso. Esses antígenos foram denominados antígenos submetidos a ultra-som $B$. ovis (ASO) e B. canis $(A S C)$ e 
corresponderam aos antígenos citoplasmáticos citados por Zoha e Carmichael (1982b).

\section{Obtenção de soro hiperimune}

\section{Canino}

Utilizou-se uma cadela, sem raça definida, de $18 \mathrm{~kg}$ e idade estimada em dois anos. Inoculou-se, por via intraperitoneal, $2 \mathrm{~mL}$ de uma suspensão de $B$. canis amostra-padrão RM 6/ 66 viva em concentração correspondente ao tubo 3 da escala MacFarland.

\section{Ovino}

Utilizou-se uma fêmea ovina, sem raça definida, de aproximadamente 1 ano de idade. $O$ animal foi inoculado por via intraperitoneal nos dias 0,16 e $88 \mathrm{com} 4 \mathrm{~mL}$ de uma suspensão de $B$. ovis viva, cepa padrão REO 198, em concentração correspondente ao tubo 3 da escala MacFarland. A terceira e última dose foi associada a $1 \mathrm{~mL}$ de betametasona (Biprospan Pharlab) com a finalidade de aumentar a suscetibilidade à infecção.

\section{Retrocultivo das amostras de sangue ovino e canino}

A partir das amostras de sangue da cadela e do ovino inoculados, coletadas em intervalos de sete a 15 dias, foram realizados 16 retrocultivos, dentro de um período de 160 dias para o canino e dez retrocultivos, em 92 dias, para o ovino; através de inoculação em caldo Tripticase Soja em garrafas de Roux, contendo Ágar e Caldo Tripticase Soja (Meio de Castañeda).

A metodologia utilizada para a obtenção do retrocultivo seguiu a orientação de Moore e Gupta(1970) e Alton et al. (1988).

A confirmação do isolamento era feita através da avaliação das características das colônias, do aspecto morfotintorial após coloração de esfregaços pelo método de Gram e da identificação através das provas de catalase, oxidase, motilidade, hidrólise da uréia, produção de $\mathrm{H}_{2} \mathrm{~S}$, produção de indol, redução de nitrato, fermentação da glicose e crescimento nos corantes Fucsina e Tionina (Alton et al., 1988).

\section{Desenvolvimento da técnica de Imunodifusão em gel de agarose (IDGA)}

Para a confecção das provas de IDGA utilizou-se $1 \mathrm{~g}$ de Agarose Tipo II AEO (SIGMA USA) adicionada a $5 \mathrm{~mL}$ de tampão borato $0,1 \mathrm{M}, \mathrm{pH} 8,3$ mais $95 \mathrm{~mL}$ de uma solução de $\mathrm{Na}$ $\mathrm{Cl}$ a $5 \%$ e $1 \mathrm{~mL}$ de uma solução de azida sódica a $1 \%$. A mistura foi aquecida em banho-maria fervente até se tornar translúcida. Distribuia-se $4 \mathrm{~mL}$ do gel de agarose por lâmina $(25 \times 75 \mathrm{~mm})$ que, posteriormente, era perfurada com uma roseta de metal contendo um orifício central e seis periféricos formando-se os poços onde eram depositados 0 antígeno $e$ os soros a serem testados, operação esta realizada com pipetas automáticas de $50 \mu \mathrm{L}$ até o preenchimento total do orifício. Cada lâmina comportava duas rosetas. As lâminas carregadas com soro e antígeno eram incubadas em câmara úmida e a leitura feita sob luz indireta às $24 \mathrm{~h}, 48 \mathrm{~h}$ e $72 \mathrm{~h}$ ( $\pm 6 \mathrm{~h}$ ) em temperatura de $25-30^{\circ} \mathrm{C}$.

O aparecimento de linha de precipitação entre os orifícios de soro e antígeno, sua localização e curvatura eram interpreta- das como resultado positivo, e a formação de ângulos entre elas caracterizava sua identidade sorológica.

\section{Controle da técnica de Imunodifusão}

Para referendar os antígenos e soros produzidos utilizou-se um "kit diagnóstico" intitulado Antígeno para Diagnóstico de Brucella ovis e Brucella canis, abricado pelo Instituto de Tecnologia do Paraná; elaborado com $B$. ovis, constituido de um frasco de antígeno liofilizado considerado antígeno padrão de referência TECPAR (ATP), três frascos de soro controle positivo (STP) e um frasco de diluente.

\section{Avaliação dos antígenos externos e antígenos submetidos a ultra-som de $B$. ovis e $B$. canis em animais experimentalmente infectados}

Esses antígenos foram utilizados para reação de imunodifusão com todas as amostras de soro obtidas da cadela e da ovelha, durante todo o experimento. Foram submetidos, ainda, à reação com o soro controle positivo do "kit diagnóstico" de referência.

\section{Avaliação dos antígenos externos e antígenos submetidos a ultra-som de B. ovis e B. canis em animais naturalmente infectados}

Foram avaliados 12 cães pertencentes a um canil comercial localizado em Barra de Guaratiba, RJ, constituido por animais de raças variadas, mantidos em grupos, em residências adaptadas. Animais desse canil apresentaram, há cerca de quatro meses, histórico de problemas reprodutivos tais como presença de abortos e de natimortos.

Os animais foram testados sorologicamente pela prova de IDGA com antígenos externos (AEO e AEC), com antígenos submetidos a ultra-som (ASO e ASC) e com o antígeno padrão de referência (ATP). Foram realizadas, ainda, hemocultura dos 12 animais através das técnicas já anteriormente descritas.

\section{Resultados e Discussão}

\section{Retrocultivo das amostras de sangue}

Dentre os 16 cultivos realizados a partir de amostras de sangue da cadela inoculada foram obtidos dez retrocultivos positivos, sendo o primeiro 54 dias após a inoculação no animal. Os isolamentos foram obtidos simultaneamente, a partir da metodologia utilizada, e identificados como $B$. canis pelas características anteriormente descritas.

De acordo com os trabalhos desenvolvidos por Carmichael (1976), Currier et al. (1982) e Berthelot e Garin-Bastuji (1993), a infecção por $B$. canis determina prolongada bacteremia que pode persistir por dois anos ou mais; Johnson e Walker (1992) afirmam que a bacteremia é detectável a partir de duas a quatro semanas após o início da infecção, podendo persistir por seis a 64 meses; já Leonard (1983) enfatiza, ainda, que a mesma pode ser intermitente. Segundo Smeak et al. (1987), a bacteremia embora possa persistir por longo tempo, pode ter um caráter transitório. No presente trabalho, dentre os 16 cultivos realizados a partir das amostras de sangue da cadela experimentalmente inoculada, foram obtidos dez retrocultivos positivos, que se mantiveram desde 54 dias pós inoculação até o final do experimento, aos 160 dias. 
Dentre os dez retrocultivos realizados a partir de amostras de sangue ovino não foram obtidos resultados positivos, dentro de um período de três meses, o que concorda com Cerri et al. (2000) que, trabalhando com animais experimentalmente infectados, também não obtiveram hemocultura positiva.

\section{Avaliação dos antígenos obtidos}

\section{Identidade com o antígeno padrão}

Os antígenos externos AEO e AEC foram testados por IDGA, frente ao "kit de referência" havendo completa identidade caracterizada por linha de imunoprecipitação única, com nítida angulação (Figura 1).

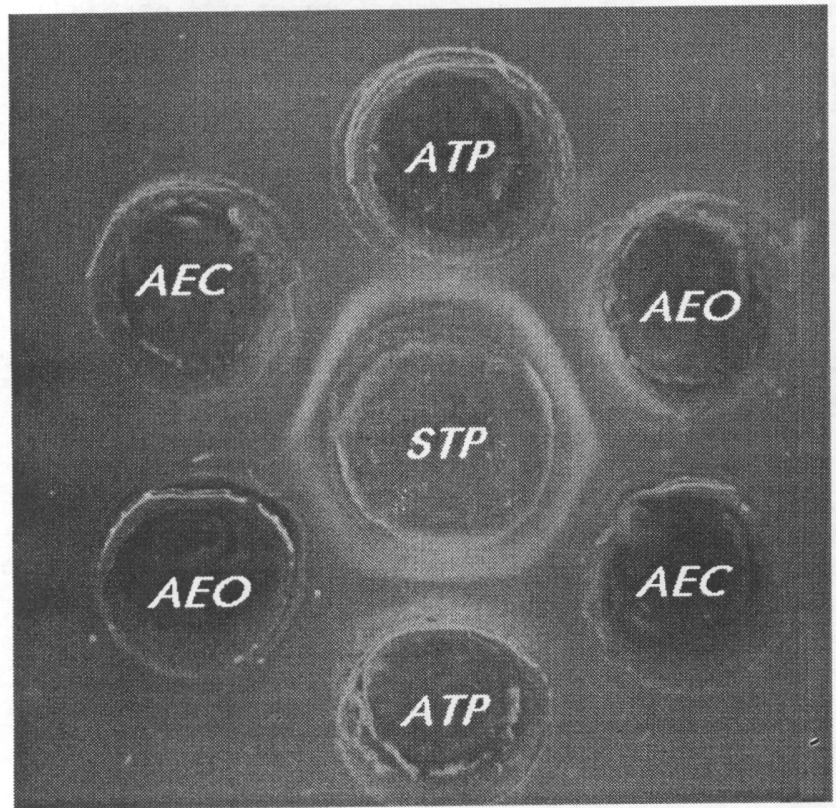

Figura 1 - Identidade dos antígenos AEO, AEC e ATP frente ao soro padrăo positivo de referência (STP - soro padrão positivo de referência; ATP - antígeno padrão de referência; $A E O$-antígeno externo $B$. ovis; AEC - antígeno externo $B$. canis)
Todas as etapas de avaliação dos antígenos produzidos foram referendadas pelo "kit padrão de referência" anteriormente descrito.

No presente trabalho foram obtidas linhas de precipitação única e de completa identidade com o "kit de referência", resultados que estão em concordância com aqueles obtidos por Myers e Varela-Diaz (1980), que afirmam que esse tipo de antígeno produz uma única linha de precipitação. Entretanto Zoha e Carmichael (1982a) obtiveram três claras linhas de precipitação com o antígeno de parede celular extraído com PBS a quente.

Os antígenos ASO e ASC testados de maneira similar não apresentaram reatividade com o "kit de referência", o que demonstra a natureza diferenciada do antígeno obtido por ultra-som.

\section{Soroconversão}

A cadela experimentalmente infectada apresentou soroconversão aos 19 dias para os antígenos AEO e ATP, aos 27 dias para todos os antígenos externos e aos 158 dias para os antígenos sonicados, o que concorda com os trabalhos de Zoha e Carmichael (1982b) que obtiveram soroconversão a partir de 30 dias para antígenos externos, a partir de oito cães, experimentalmente infectados ao nascer. Em relação aos antígenos obtidos por ultra-som, nossos achados concordam com Carmichael et al. (1984), que afirmam que a reação positiva em cães, para antígeno sonicado, se dá a partir de 16 semanas de infecção. Em relação ao ovino, a soroconversão ocorreu para os três antígenos externos testados aos 16 dias pós-inoculação, fato esse concordante com Cerri et al. (2002) que, trabalhando com oito ovinos experimentalmente inoculados, obtiveram soroconversão aos 15 dias, até se tornarem sorologicamente negativos na $24^{a}$ semana pós-inoculação. A soroconversão para os antígenos obtidos por ultra-som se deu aos 92 dias pós inoculação. Outro trabalho realizado por Cerri et al. (2000), comparando vários procedimentos sorológicos. em ovinos, também deu suporte ao experimento aqui realizado, quando afirmaram que a IDGA apresentou $100 \%$ de especificidade e $100 \%$ de sensibilidade.

\section{Avaliação dos animais naturalmente infectados}

Tabela 1 - Resultado da avaliação sorológica e bacteriológica em animais de um canil suspeitos de infecção por $B$. canis

\begin{tabular}{|c|c|c|c|c|c|c|c|c|c|}
\hline \multirow[t]{2}{*}{ Animal } & \multirow[t]{2}{*}{ Sexo } & \multirow[t]{2}{*}{ Raça } & \multirow[t]{2}{*}{ Aborto } & \multicolumn{5}{|c|}{ RESULTADO DA IDGA } & \multirow{2}{*}{$\begin{array}{l}\text { Hemo } \\
\text { cultura }\end{array}$} \\
\hline & & & & ATP & AEO & AEC & ASO & ASC & \\
\hline 1 & $\mathrm{~m}$ & Husky & & - & - & - & - & - & - \\
\hline 2 & $m$ & Beagle & & - & - & - & - & - & - \\
\hline 3 & $f$ & Cocker & não & - & - & - & - & - & - \\
\hline 4 & $f$ & Cocker & não & - & - & - & - & - & - \\
\hline 5 & $f$ & Cocker & não & - & - & - & - & - & - \\
\hline 6 & $\mathrm{~m}$ & Cocker & & - & + & - & - & - & - \\
\hline 7 & $f$ & Cocker & $\operatorname{sim}$ & - & + & - & - & - & - \\
\hline 8 & $f$ & Cocker & $\operatorname{sim}$ & + & + & - & - & - & * \\
\hline 9 & $f$ & Cocker & $\operatorname{sim}$ & + & + & - & - & - & * \\
\hline 10 & $f$ & Beagle & $\operatorname{sim}$ & + & + & + & + & + & + \\
\hline 11 & $f$ & Cocker & não & + & + & + & + & + & + \\
\hline 12 & $f$ & Cocker & sim & + & + & + & + & + & + \\
\hline
\end{tabular}

ATP - antígeno padrão de referência; AEO - antígeno externo B. ovis; AEC - antígeno externo $B$. canis;

ASO - antígeno obtido por ultra-som de B. ovis; ASC - antígeno obtido por ultra-som de $B$. canis.

(*) não confirmada 
Dentre os 12 animais avaliados sorológica e bacteriologicamente (Tabela 1), os caninos 10,11 e 12 reagiram a todos os antígenos produzidos neste trabalho, bem como ao antígeno de referência apresentando, ainda, hemoculturas positivas para B.canis confirmadas por provas bioquímicas anteriormente citadas. Esses resultados permitiram qualificar os antígenos produzidos.

Os resultados referentes aos antígenos submetidos ao ultrasom (ASO e ASC) sugerem uma prolongada exposição ao agente, já que esses animais são provenientes de zonas urbanas, sendo negado o contato com animais de produção pecuária, o que excluiria a possibilidade de reações cruzadas com outras espécies do gênero Brucella conforme descrito por Carmichael e Shin (1996).

Os animais 8 e 9 provavelmente se encontravam numa fase de evolução da doença anterior aos demais e os animais 6 e
7, que só se apresentaram positivos ao $A E O$, sugerem animais em fase inicial da infecção e apontam, ainda, para uma maior sensibilidade do antígeno AEO, a despeito dele ser semelhante ao antígeno padrão (ATP), em função, provavelmente, de uma maior concentração do primeiro.

\section{Conclusão}

Pelo presente trabalho concluiu-se que os antígenos externos se mostraram superiores aos antígenos submetidos ao ultra-som pela produção de bandas mais visiveis e detecção mais precoce, através da prova de Imunodifusão em Gel de Agarose, tanto em animais experimentalmente quanto naqueles naturalmente infectados. A utilização simultânea do antígeno submetido ao ultra-som é importante para validar esse resultado.

\section{Agradecimentos}

Ao Dr. Jorge Victor Bacilla Agotanni, do Laboratório TECPAR pela cessão do "kit de referência".

Ao Dr. Wildeberg Cál Moreira, do Laboratório de Diagnóstico de Raiva do Instituto de Medicina Veterinária Jorge Vaistman, pela colaboração e assessoria no processamento dos antígenos.

Ao Dr. Geraldo Baeta da Cruz, do Laboratório de Ecofisiologia da EMBRAPA, e ao Prof. Dr. Walter Flausino, da Universidade Federal Rural do Rio de Janeiro, pela colaboração na utilização do ultra-som.

\section{Referências}

ALTON, G G; JONES, L. M.;ANGUS, R. D.; VERGER, J. M. Techniques for the brucellosis laboratory. Paris: INRA, 1988.

BERTHELOT, X.; GARIN-BASTUJI, B. Brucelloses canines. Point Vét., V. 25, n. 152 , p. $125-129,1993$.

CARMICHAEL, L. E. Abortion in 200 Beagles. News Report. J. Amer. Vet. Med. Ass., v. 149, n. 8, p. 1126, 1966.

CARMICHAEL, L. E. Canine Brucellosis: an anotated review with selected cautionary comments. Theriogenology, v. 6, n. 2-3, p. 105$116,1976$.

CARMICHAEL, L. E.; ZOHA, S. J.; FLORES-CASTRO, R. Problems in the serodiagnosis of canine brucellosis: dog response to cell wall and internal antigens of Brucella canis. Dev. Biol.Stand., v. 56, p. 371-383, 1984.

CARMICHAEL, L. E.; SHIN, S. J. Canine brucellosis: a diagnostician's dilemma. Semin. Vet. Med. Surg. (Small Animal), v. 11, n. 3, p. 161$165,1996$.

CERRI, D.; EBANI, V. V.; BASSI, S.; BEY, R. F.;ANDREANI, E.; FARINA, $R$. Evaluation of tests employed in serological diagnosis of brucellosis caused by Brucella ovis. New Microbiology, v. 23, n. 3, p. 281-288, 2000.

CERRI, D.;AMBROGI, C.; EBANI, V. V.; CAPELLI, F.; CARDINI, G.; ANDREANI, E. Experimental Brucella ovis infection in mouflon (Ovis musimon). J. Wildl. Dis., v. 38, n. 2, p. 287-290, 2002.

CORBEL, M. J. Brucellosis: an overview. Emerging Infectious Disease, V. 3, p. 213-221, 1997.

CURRIER, R. W.; RAITHEL, W. F.; MARTIN, R. J.; POTTER, M. E. Canine brucellosis. J. Amer. Vet. Med. Ass., v. 180, n. 2, p. 132-133, 1982.

GERMANO, P. M. L.; VASCONCELLOS, S. A.; ISHIZUKA, M. M; PASSOS, E. C.; ERBOLATO, E. B. Prevalência de infecção por Brucella canis em cães da cidade de Campinas, SP, Brasil. Rev. Fac. Med. Vet. Zootec. Univ. de São Paulo, v. 24, n. 1, p. 27-34, 1987.
GOMES, M. J. P; DRIEMEIER, D.; SOARES, H.; BASTOS, C. D.; CANTO, S. P.; BRUM, M.; ROSSI,A. C.; CORBELLINI, L. G. Brucella canis: isolamento em um cão com epididimite e orquite - relato de um caso. Clinica Veterinária, n. 18, p. 17-20, 1999.

JOHNSON, C.A; WALKER. R. D. Clinical signs and diagnosis of Brucella canis infection. Comp. Cont. Ed. Pract. Vet., v. 14, n. 6, p. 763-772, 1992.

LEONARD, J. L. Canine brucellosis testing. (Letters). J. Amer. Vet. Med. Ass., v. 183, n. 11, p. 1133, 1983.

LUCERO, N. E.; ESCOBAR, G I.;AYALA, S. M.; LOPEZ, G. Sensitivity and specificity of an indirect enzyme-linked immunoassay for the diagnosis of Brucella canis infection in dogs. J.Med.Microbiol., v. 51, p. 656-660, 2002.

MATEO-DE-ANTONIO, E. M.; MÁRTIN, M.; CASAL, J. Comparison of serologic tests used in canine brucellosis diagnosis. J.Vet. Diagn. Invest., v. 6, p. 257-259, 1994.

MOORE, J.A.; GUPTA, B. N. Epizootiology, diagnosis and control of Brucella canis, J. Amer. Vet. Med. Ass. v. 156, n. 12, p. 1737-1742, 1970.

MYERS, D. M.; VARELA-DIAZ, V. M. Serological and bacteriological detection of Brucella canis infection of stray dogs in Moreno, Argentina. Cornell Vet., v. 70, p. 258-265, 1980.

SHAPIRO, D. S.; WONG J. D. Brucella In: MURRAY, P. R.; BARON, E. J.; PFALLER, M. A.; TNOVER, F. C.; YOLKEN, R. H. Manual of Clinical Microbiology. 7: ed. Washington American Society for Microbiology, 1999. p. 625-631.

SMEAK, D. D.; OLMSTEAD, M. L.; HOHN, R. B. Brucella canis osteomyelitis in two dogs with total hip replacements J.Am. Vet.Med.Ass., v. 191, n. 8, p. 986-990, 1987.

ZOHA, S. J.; CARMICHAEL, L.. E. Properties of cell wall antigens of virulente Brucella canis and a less mucoid variant of reduced pathogenicity. Am. J. Vet. Res., v. 43, p. 171-174, 1982a.

ZOHA, S. J.; CARMICHAEL, L. E. Serological responses of dogs to cell wall and internal antigens of Brucella canis. Vet. Microbiol., v. 7, p. $35-50,1982 b$. 